\title{
The effect of air-fuel equivalence ratio change on the vibration components of an internal-combustion engine
}

\author{
Gabor Manhertz \\ Department of Mechatronics, Optics and Mechanical \\ Engineering Informatics \\ Budapest University of Technology and Economics \\ Budapest, Hungary \\ Corresponding author's e-mail: manhertz@mogi.bme.hu
}

\author{
Akos Antal \\ Department of Mechatronics, Optics and Mechanical \\ Engineering Informatics \\ Budapest University of Technology and Economics \\ Budapest, Hungary
}

\begin{abstract}
Nowadays the automotive industry and the motor development are one of the most dynamically developing industries. One solution to the diagnostic systems providing reliability is the acoustic and vibration measurement system, which can indicate and predict a variety of malfunctions after signal processing. The purpose of this experiment is to analyze the effect of the air-fuel equivalence ratio on the vibration components of an internal-combustion engine (ICE) which is a part of the in question measurement system. In the focus of the experiments are the analysis of the time signal, its spectra, and the power content of the signal. With the increment of the air-fuel ratio the amplitudes of the measured signal and its spectral amplitudes showed a downward trend as the RMS values. In addition, certain frequency components disappeared during the actuation of the ICE with an electromotor, so the characterization of the combustion could be come to the front.
\end{abstract}

Keywords-vibration diagnostics; internal-combustion engine; air-fuel equivalence ratio, spectra, RMS

\section{INTRODUCTION}

The automotive manufacturers are trying to adapt more from the directives of the competition on the market. To meet these requirements the best, they need to find the best compromise between the price, the operational safety, the fuel consumption, the emission limits and the performance. The performance can be influenced by the air-fuel equivalence ratio which can be resulted in the examination of the pollutant emission or the validation of mathematical models. Several references describe this kind of research works based on ICEs [1]-[3]. Besides of the air-fuel ratio, the engine characteristics and operation can be influenced with various types of fuel as well [4]. Nowadays, because of the environmental awareness, experimentally friendly fuels are used also. In [5] an experimental study can be seen on a direct injection diesel engine operated with Kapok methyl.

An internal-combustion engine has several physical values which can be measured and the results characterize the state of the engine. Vibration analysis is applied frequently as the basis of expert systems. Some of these systems are used for condition monitoring and fault diagnosis [6]-[8]. A very interesting research can be seen in reference [9] where the combination of the vibration and acoustic emission was applied. Frequency-based analysis is often used in the vibration diagnostics of ICEs. Lin et. al [10] represents a vibration diagnostic technique based on the correlation of discrete spectrum. In reference [11] the combination of the time and frequency domain analysis can be seen. It can be concluded from the literature that the vibration analysis of the ICEs is quite common and the research trends are very diverse over and above the relation between the vibration and the airfuel ratio is not a frequently discussed topic. However, the applied diagnostic methods are becoming more complex and the simple ones being forgotten or will be not applied anywhere. This research work will go back to the basic vibration diagnostic methods which made us also possible to determine correlation between the numerical results and the actual air-fuel equivalence ratio.

\section{A. The Air-fuel Equivalence Ratio}

The air-fuel equivalence ratio gives the ratio of the intake air-amount and the theoretically required air-amount for the combustion. This ratio affects the engines efficiency, performance and the pollutant emission. During the combustion, because it is a chemical process, the correct ratio of the present fuel and oxygen is a very important factor. If the amount of the air and the fuel is not close to equilibrium during the reaction, the combination of the input and output materials will not be fully.

The air-fuel equivalence ratio at the ideal - theoretic air-fuel ratio is 1 , i.e. the mixture is stoichiometric. The combustion requires that the mixture need to be between the lower and the upper flammability limit. Within this range, if the air-fuel equivalence ratio is less than 1 (i.e. the mixture is fuel-rich) the chemically bounded energy cannot fully be converted into heat - a significant amount of $\mathrm{CO}$ emission occurs. If the mixture is fuel-poor, the air-fuel equivalence 
ratio will be greater than 1 ; the mixture contains more oxygen than it is necessary for the combustion.

The air-fuel equivalence ratio is the ratio of the intake airamount and the theoretically required air-amount, so its value can be determined from oxygen concentration of the flue gas:

$$
\lambda=\frac{L}{L_{0}}=1+\left[\frac{O_{2}}{21-O_{2}}\right] \frac{V_{0}}{L_{0}} \approx \frac{20,9}{20,9-O_{2, \text { measured }}}
$$

where: $L$ is the actual air-amount, $L_{0}$ is the theoretic airamount, $V_{0}$ is the theoretic flue gas-amount.

The main task is to analyze the effect of change of the airfuel equivalence ratio on the vibration components of an internal-combustion engine.

\section{EXPERIMENTAL SETUP}

Today's modern vehicle engines are equipped with many sensors and control units which determine the required mixture for the actual operating state. The inadequate air-fuel equivalence ratio can affect other parameters analyzed by the ECM so the continuous monitoring of these parameters is the base of the diagnostics.

The vibration measurements based on a gas-powered ICE. The main part of the unit is a BAG-20 type device manufactured by Ganz-Set Ltd. which consists of the following components

- Wiscon Total TM27 type gas-engine

- Marelli CX IM B3 180M type asynchronous generator

For the measurements a single-axis knock sensor used in automotive industry manufactured by Siemens was applied. Its signal was recorded by a USB-6008 DAQ device produced by National Instruments. The data acquisition device had $12 \mathrm{bit}$ resolution and 10000samples/sec maximum sampling frequency. With these devices the lower frequency vibration of the engine were measured well but for further researches it is essential to examine the higher frequency ranges. The fuelair mixture of the engine was controlled with a valve and it was determined from the oxygen concentration of the exhaust gas. To measure the $\mathrm{O}_{2}$ concentration during the test a Servomex 570A type paramagnetic device was used.

In order to mount the knock sensor two mounting place were possible. The first was at the joint of the crank-case and the cylinder-head, the second was on the crack-case (Fig. 1). From the measurements of the first mounting place, a number of factors seemed to affect negatively the results.

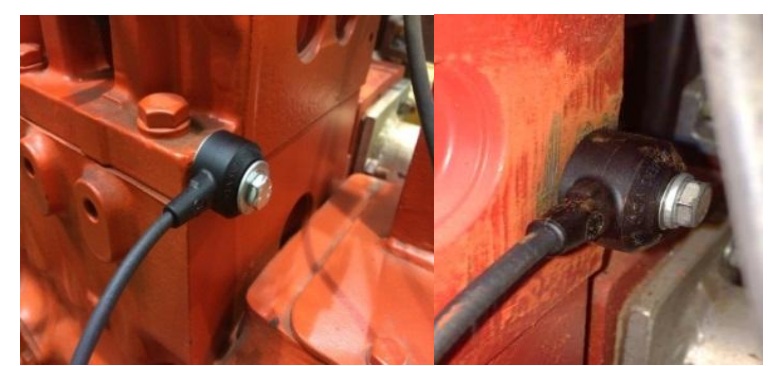

Fig. 1. The mounting of the accelerometer on the first (left) and on the second (right) mounting place

One of the problems was the mounting place itself, since the crank-case and the cylinder-head was not flush so the sensor could not abut on completely on the surface. A spacer was needed to be equipped which worked as a spring and caused up to $100 \mathrm{~m} / \mathrm{s} 2$ (henceforward [g]) acceleration values in the time signal (Fig. 2). Another problem was the thickness of the spacer because the base of the accelerometer could not still abut completely on the cast of the crank-case. The third problem was the bad vibration transmission of the painting of the engine to the sensor. On the housing was approx. a $0,3 \mathrm{~mm}$ think layer of paint which was not conducive to the measurement as well. These factors mentioned above brought major noise into the system, as well as they occurred non-real frequencies in the spectrum and the real ones have been blurred.

At the second mounting place, taking into account the experienced defects previously, the paint has been removed from the engine and the accelerometer could be able to be mounted completely on the surface without a spacer.

The results obtained with this set-up carried much more processable information. The maximum acceleration value of the measurements performed at the second mounting place nearly with the same air-fuel equivalence ratio was less than half of the previous.

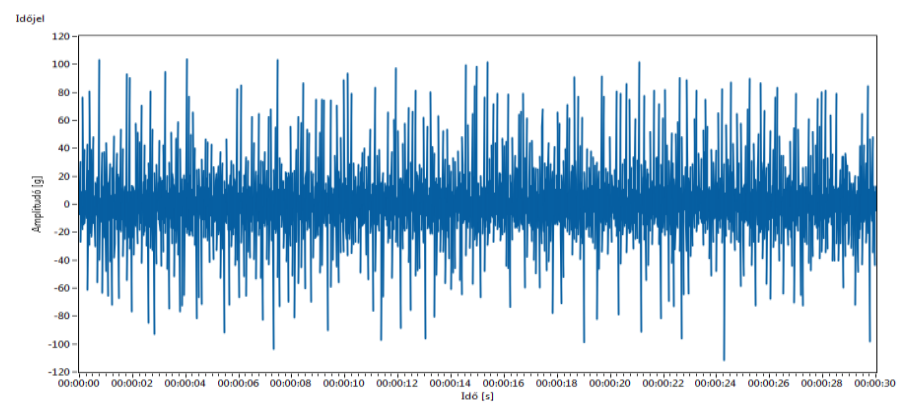

Fig. 2. The recorded time signals of sensor at the first (above) and the second (bottom) mounting place - the time [s] function of the acceleration $[\mathrm{g}]$ 


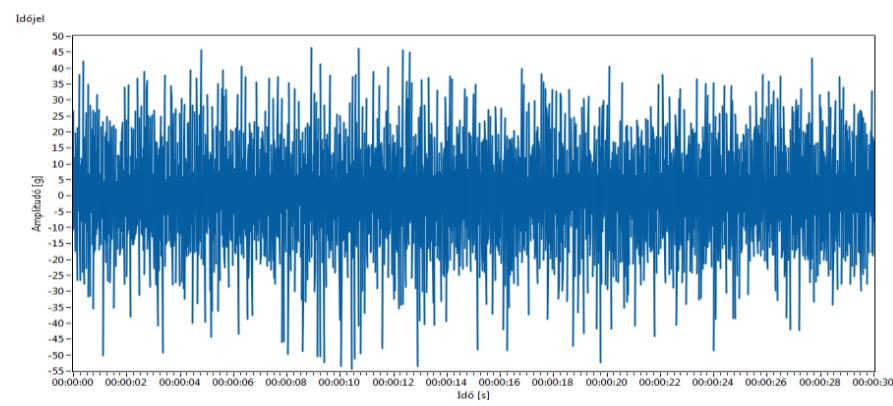

During the measurement the engine's speed was 1500 RPM (rotation per minute) which was equal to $25 \mathrm{~Hz}$. Due to the properties of the data acquisition card, the maximum computable $5000 \mathrm{~Hz}$ was suffice for the analysis of the lower frequencies. The card received voltage signal with $\mathrm{mV}$ magnitudes therefore to determine the acceleration values a conversion had to be applied. The sensitivity of the sensor was $30 \mathrm{mV} / \mathrm{g}$ which needed to be corrected by $-8,1 \mathrm{mV} / \mathrm{g}$ pro meter. The attached cable length was $0,74 \mathrm{~m}$ which decreased the original sensitivity with $6 \mathrm{mV}$ so the resulting sensitivity of the sensor was $24 \mathrm{mV} / \mathrm{g}$.

During the research three time signals were measured at warm engine under different air-fuel equivalence ratios (Table I.) as well as another signal which was recorded when there was no combustion in the engine only the asynchronous machine actuated it.

TABLE I. THE THREE PRESET AIR-FUEL EQUIVALENCE RATIO VALUES DURING THE MEASUREMENTS

\begin{tabular}{|c|c|}
\hline $\begin{array}{c}\boldsymbol{O}_{2} \text { content of } \\
\text { the exhaust gas } \\
\text { [\%] }\end{array}$ & $\begin{array}{c}\text { Air-fuel } \\
\text { equivalence } \\
\text { ratio [-] }\end{array}$ \\
\hline 1,3 & 1,063 \\
\hline 3,9 & 1,214 \\
\hline 7,6 & 1,515 \\
\hline
\end{tabular}

\section{THE EVALUATION OF THE MEASUREMENT RESULTS}

The measurements were carried out on constant rpm, so as a consequence the frequency components of the signal should have changed only a little. This can be verified if the time signal was subject to the STFT $^{1}$ transformation [12] with which the time-frequency-amplitude function, the so-called Waterfall-diagram could be plotted.

The STFT principles are the same as the fast Fourier transform but in this case the transform is executed at specific time steps and its frequency resolution is much less. If during the measurement the spectra would have changed, it would be clearly visible on the diagram.

On the signal measured at the lowest air-fuel equivalence ratio such transformation has been executed on which it is clearly visible that the spectrum does not change in time significantly as it was expected. On the three-dimensional diagram the spectra can be seen between 20 and 32,6 seconds with a step size of 0,7 seconds. The illustrated frequency range is the $0-700 \mathrm{~Hz}$ interval.

To evaluate the measurements at the given air-fuel equivalence ratios the amplitudes of the time signals, the spectral amplitudes and components, and the power content $\left(\mathrm{RMS}^{2}\right.$ value) of the signal should be analyzed.

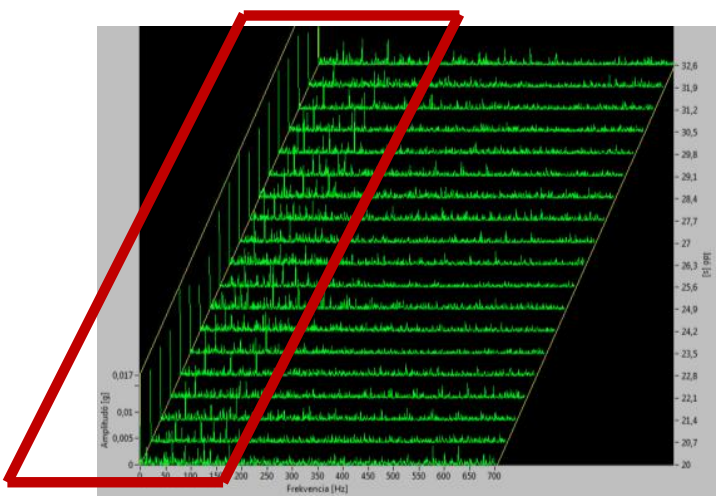

Fig. 3. STFT transform performed at the lowest air-fuel equivalence ratio (the time $[\mathrm{s}]$ function of the amplitude $[\mathrm{g}]$ and the frequency $[\mathrm{Hz}]$ )

\section{A. The Analysis Of The Time Signals}

In the table below the maximum and minimum amplitude values of the entire time signals are shown.

TABLE II. THE MAXIMUM AND MINIMUM AMPLITUDE VALUES OF THE FOUR MEASUREMENT SETUP AS A FUNCTION OF THE AIR-FUEL EQUIVALENCE RATIO

\begin{tabular}{|c|c|c|}
\hline $\begin{array}{c}\text { Air-fuel } \\
\text { equivalence } \\
\text { ratio [-] }\end{array}$ & $\begin{array}{c}\text { Maximum } \\
\text { acceleration [s] }\end{array}$ & $\begin{array}{c}\text { Minimum } \\
\text { acceleration [s] }\end{array}$ \\
\hline 1,063 & 46,57 & $-54,645$ \\
\hline 1,214 & 36,81 & $-38,306$ \\
\hline 1,515 & 31,51 & $-32,491$ \\
\hline$\infty$ & 29,38 & $-28,97$ \\
\hline
\end{tabular}

The table shows that the maximum and minimum amplitudes of the time signals have a decreasing as function of the air-fuel equivalence ratio. This means that the degradation of the air-fuel mixture, i.e. the step-by-step garbling of the perfection of the combustion, the vibration components were decreasing. In the case of no combustion (actuation with the asynchronous machine) were the vibration components the lowest. This led to the conclusion that the combustion itself could affect the vibration of the engine.

\section{B. The Analysis Of The Spectra}

Based on the results of the STFT analysis, the Fourier transformation could be used to determine the spectral components. Figure 4 shows the spectra of a time signal

\footnotetext{
${ }^{2}$ Root Mean Square
}

\section{${ }^{1}$ Short-Time Fourier Transform}


belongs to $\lambda=1,063$ air-fuel equivalence ratio. For the traceability of the later analysis that frequency component was marked which belongs to the rev of the engine $(25 \mathrm{~Hz})$. In addition, this frequencies multiplies could be found which could be a result of the operation of the various engine components.

Several components of the engine depend on the rev of the crankshaft thus that could be identified which component belongs to which harmonic or spectral component. The rev of the camshaft is the half of the rev of the crankshaft so the related frequency component is $12,5 \mathrm{~Hz}$. The $50 \mathrm{~Hz}$ component may be in connection with the combustion process but the electrical $50 \mathrm{~Hz}$ was also presenting significant. Due to the four cylinders the combustion occurred in two cylinders pro a rotation and the frequency of the asynchronous machine changed this component as well.

On the spectra of the measurements at three different airfuel equivalence ratios it could be seen that the amplitudes of the components were progressively decreasing (Fig. 8) or even disappeared in the background noise. As regards to the analysis of the harmonic components, that signal recorded at actuation of the engine with asynchronous machine was also analyzed (Fig. 7). On this it could be seen that the $48,5 \mathrm{~Hz}$ component is much higher than the $25 \mathrm{~Hz}$ component. At this case two prominent frequencies should be highlighted. The first one is the $48,5 \mathrm{~Hz}$ component which derived from the $50 \mathrm{~Hz}$ of the generator as well as from its characteristic $3 \%$ slip. The rotor of the generator has four poles so its forth harmonic frequency is $194 \mathrm{~Hz}(4 \mathrm{x} 48,5=194 \mathrm{~Hz})$.

Comparing the spectra with each other, it can be concluded that in the case of the disappearance of the frequency components at asynchronous machine actuation, and the decreasing of the amplitudes (the combustion frequencies were not superponated onto the other components) were resulted from the character (or the existence) of the combustion. The frequencies which completely disappeared at the low-frequency range: $75 \mathrm{~Hz}, 100 \mathrm{~Hz}, 112,5 \mathrm{~Hz}, 125 \mathrm{~Hz}$, $150 \mathrm{~Hz}$.

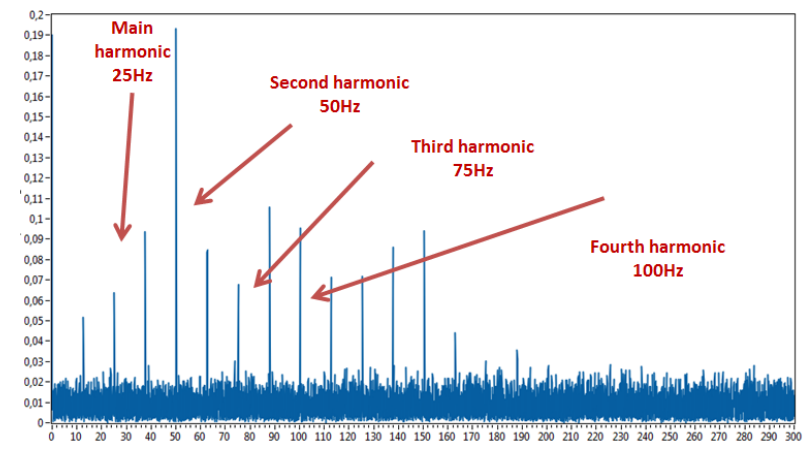

Fig. 4. Spectra at $\lambda=1,063$ air-fuel equivalence ratio (the frequency [Hz] function of the acceleration $[\mathrm{g}])$

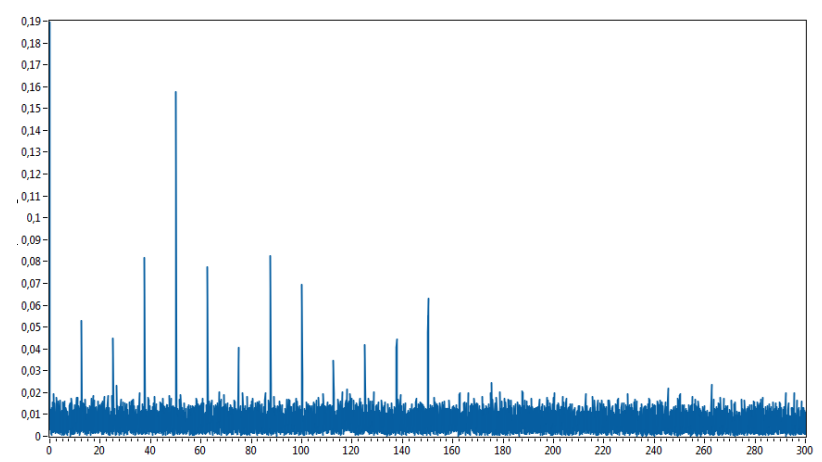

Fig. 5. Spectra at $\lambda=1,214$ air-fuel equivalence ratio (the frequency [Hz] function of the acceleration $[\mathrm{g}]$ )

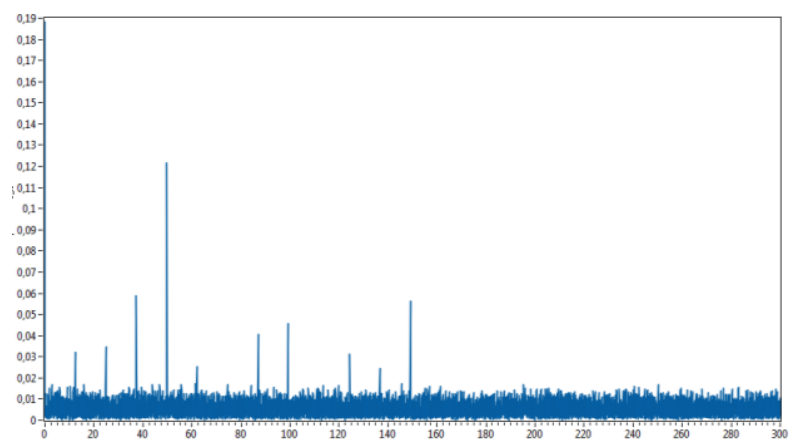

Fig. 6. Spectra at $\lambda=1,515$ air-fuel equivalence ratio (the frequency [Hz] function of the acceleration $[\mathrm{g}])$

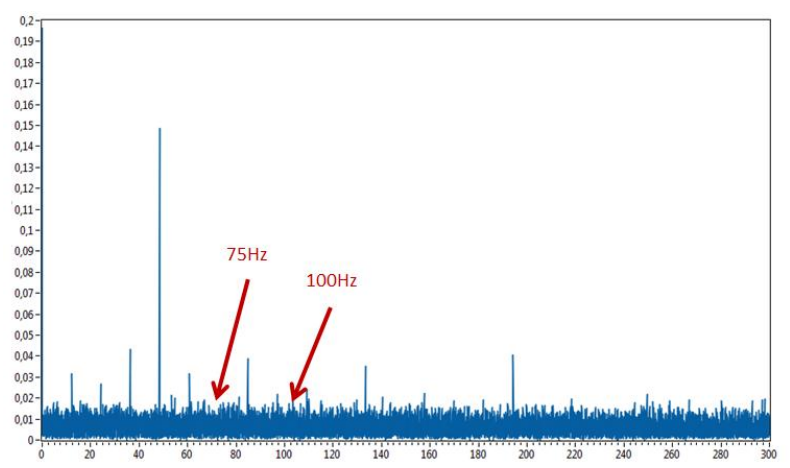

Fig. 7. Spectra at the actuation with the asynchronous machine (the frequency $[\mathrm{Hz}]$ function of the acceleration $[\mathrm{g}]$ ) 


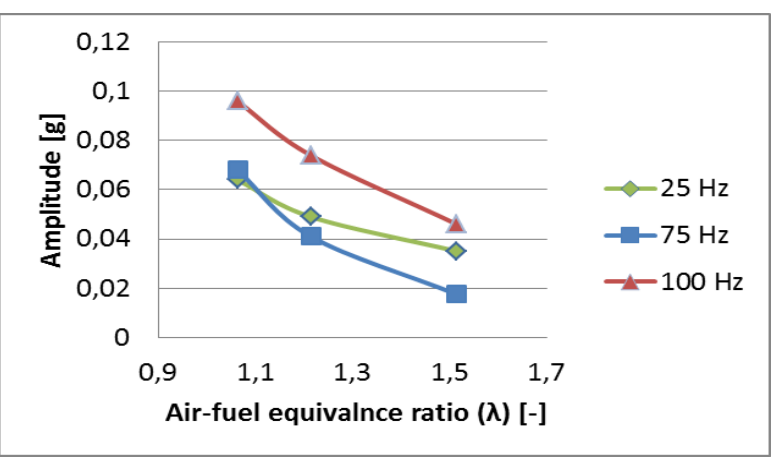

Fig. 8. The changes of the amplitudes of some frequency component as a function of the air-fuel equivalence ratio

\section{Power Content}

In vibration diagnostics and analysis, a generally accepted measure is the RMS value of the signal which represents the power content of the studied signal section in a numerical form. This power content is derived from the selected variable integral of the analyzed section. During the post-processing, the time signal and the spectra RMS value was calculated with the following formulas [12]:

In case of time signal:

$g_{\text {RMS }}=\sqrt{\frac{1}{t_{2}-t_{1}} \int_{t_{1}}^{t_{2}} f^{2}(t) d t}$

In case of spectra:

$g_{\varpi_{R M S}}=\sqrt{\frac{1}{\varpi_{2}-\varpi_{1}} \int_{\varpi_{1}}^{\varpi_{2}} f^{2}(\varpi) d \varpi}$

As here the power content was the main point of the analysis that cases was needed to be studied when there was combustion in the engine, i.e. the asynchronous machine actuation was irrelevant in this case.

Before processing the measurement results the decreasing of the RMS values were expected as the function of the airfuel equivalence ratio. The theoretical explanation of this is (as before) because of the degradation of the mixture the combustion will be shifted from the $\lambda=1$ value required for the perfect combustion, so the effective medium pressure and thereby the torque will be reduced.

The results (Table III.) were as expected. This means that all of the RMS values of the time signals and the spectrum showed a decreasing trend do to the increase of the air-fuel equivalence ratio.

TABLE III. THE RMS VALUES OF THE TIME SIGNAL AND THE SPECTRA AS FUNCTION OF THE AIR-FUEL EQUIVALENCE RATIO

\begin{tabular}{|c|c|c|}
\hline $\begin{array}{c}\text { Air-fuel } \\
\text { equivalence } \\
\text { ratio [-] }\end{array}$ & $\begin{array}{c}\text { Time signal } \\
\text { RMS } \\
\text { [g } \text { RMS] }\end{array}$ & $\begin{array}{c}\text { FFT amplitude } \\
\text { RMS [g RMS] } \\
(\mathbf{0 - 3 0 0 H z})\end{array}$ \\
\hline 1,063 & 2,57438 & 0,01080030 \\
\hline 1,214 & 2,11306 & 0,00814465 \\
\hline 1,515 & 2,06645 & 0,00659716 \\
\hline
\end{tabular}

\section{Further research opportunities}

To improve and support the research results further measurements are necessary e.g. with less than one air-fuel equivalence ratio, variable rev and load, radial vibration measurements and with the use of a data acquisition card having higher resolution and sampling frequency. With these results a complex engine characteristic will be able to obtained.

\section{CONCLUSION}

The experimental results showed that with the increase of the air-fuel equivalence ratio of a gas engine operating at a constant speed, the amplitudes of the measured signals and spectrum decreased as well as their RMS values - the power content.

This means that numerical results of the basis vibration diagnostic methods are able to show correlations and trends between the air fuel ration and the vibration of a gas engine.

During the measurements the engine was actuated with an asynchronous machine as well - there was no combustion in the combustion chamber. As a result, compared to the cases with combustion, the amplitude values were the least and spectral components disappeared.

The reason could be that there was no combustion, so its spectral components were not present and were not added to the vibrations originated from the mechanical system. Based on this observation it can be concluded that the high frequency vibrations caused by the combustion may be detectable with proper algorithms.

\section{References}

[1] [A] C-W. Wu, R-H. Chen, J-Y. Pu, T-H. Lin, "The influence of air-fuel ratio on engine performance and pollutant emission of an SI engine using ethanol-gasoline-blended fuels," Athmospheric Environment, vol. 38(40), pp. 7093-7100, 2004

[2] [B] F.Y. Hagos, A.R.A. Aziz, S. A. Sulaiman, "Effect of Air-fuel Ratio on Comubstion Characterstics of Syngas (H2:CO) in Direct-injection Spark-ignition Engine, "Energy Procedia, vol 61, pp. 2567-2571, 2014

[3] [C] R. Ebrahimi, "Performance analysis of an irreversible Miller cycle with considerations of relative air-fuel ratio and stroke length," Applied Mathematical Modelling, vol. 36(9), pp. 4073-4079, 2012

[4] [D] Y. Huang, C.J. Sung, J.A. Eng, "Effects of n-butane addtion on reformer gas combustion: Implications for the potential of using reformer gas for an engine cold start," Proceedings of the Combustion Institute, vol 29(1), pp. 759-765, 2002 
Recent Innovations in Mechatronics (RIiM) Vol. 2. (2015). No. 1-2.

DOI: 10.17667/riim.2015.1-2/13.

[5] [E] T.S. Kumar, P. S. Kumar, K. Annamalai, "Experimental study on the performance and emission measures of direct injection diesel engine with Kapok methyl ester and its blends," Renewable Energy, vol. 74, pp. 903-99, 2015

[6] [F] Z. Geng, J. Chen, "Investigation into piston-slap-induced vibration for engine condition simulation and monitoring," Journal of Sound and Vibration, vol. 282(3-5), pp. 735-751, 2005

[7] [G] L. Barelli, G. Bidini, C. Buratti, R. Mariani, "Diagnosis of internal combustion engine through vibration and acoustic pressure non-intrusive measurements," Applied Thermail Engineering, vol. 29(8-9), pp. 17071713, 2009

[8] [H] Z. Geng, J. Chen, J. B. Hull, "Analysis of engine vibration and design of an applicable diagnosing approach," Int. J. of Mechanical Sciences, vol. 45, pp. 1391-1410, 2003

[9] [I] J-D. Wu, C-Q. Chuang, "Fault diagnosis of internal combustion engines using visual dot patterns of acoustic and vibration signals," NDT\&E International, vol. 38, pp. 605-614, 2005
[10] [J] H. Lin, K. Ding, "A new method for measuring engine rotational speed based on the vibration and discrete spectum correction technique," Measurement, vol. 46(7), pp. 2056-2064, 2014

[11] [K] O.M. Boaghe, S.S. Bllings, L.M. Li, P.J. Fleming, J. Liu, "Time and frequency domain identicitaion and analsys of a gas turbine engine," Control Engineering Practice, vol. 10(12)m pp. 1347-1356, 2002

[12] [L] S. Vulli, J.F. Dunne, R. Potenza, D. Richardson, P. King, "Timefrequency analysis of single-point engine-block vibration measurements for multiple excitation-event identification," Journal of Sound and Vibration,vol. 321, pp. 1129-1143, 2009

[13] [M] G. Gardonyi, G. Manhertz: Vibration diagnostic algorithms for studying electromotive drivetrain (in Hungarian), Proceedings of 16th Spring Wind International PhD Conference, Sopron, vol. 1, pp. 169-177, 2013 